From:

Architecture /Mouvement/ Continuité

October, 1984;

("Des Espace Autres," March 1967

Translated from the French by Jay Miskowiec)

Of Other Spaces: Utopias and Heterotopias

\title{
MICHEL FOUCAULT
}

The great obsession of the nineteenth century was, as we know, history: with its themes of development and of suspension, of crisis, and cycle, themes of the ever-accumulating past, with its great preponderance of dead men and the menacing glaciation of the world. The nineteenth century found its essential mythological resources in the second principle of thermodynamics. The present epoch will perhaps be above all the epoch of space. We are in the epoch of simultaneity: we are in the epoch of juxtaposition, the epoch of the near and far, of the side-by-side, of the dispersed. We are at a moment, I believe, when our experience of the world is less that of a long life developing through time than that of a network that connects points and intersects with its own skein. One could perhaps say that certain ideological conflicts animating present-day polemics oppose the pious descendents of time and the determined inhabitants of space. Structuralism, or at least which is grouped under this slightly too general name, is the effort to establish, between elements that could have been connected on a temporal axis, an ensemble of relations that makes them appear as juxtaposed, set off against one another, implicated by each other-that makes them appear, in short, as a sort of configuration. Actually, structuralism does not entail denial of time; it does involve a certain manner of dealing with what we call time and what we call history.

Yet it is necessary to notice that the space which today appears to form the horizon of our concerns, our theory, our systems, is not an innovation; space itself has a history in Western experience, and it is not possible to disregard the fatal intersection of time with space. One could say, by way of retracing this history of space very roughly, that in the Middle Ages there was a hierarchic ensemble of places: sacred places and profane places: protected places and open, exposed places: urban places and rural places (all these concern the real life of men). In cosmological theory, there were the supercelestial places as opposed to the celestial, and the celestial place was in its turn opposed to the terrestrial place. There were places where things had been put because they had been violently displaced, and then on the contrary places where things found their natural ground and stability. It was this complete hierarchy, this opposition, this intersection of places that constituted what could very roughly be called medieval space: the space of emplacement.

This space of emplacement was opened up by Galileo. For the real scandal of Galileo's work lay not so much in his discovery, or rediscovery, that the earth revolved around the sun, but in his constitution of an infinite, and infinitely open space. In such a space the place of the Middle Ages turned out to be dissolved, as it were; a thing's place was no longer anything but a point in its 
movement, just as the stability of a thing was only its movement indefinitely slowed down. In other words, starting with Galileo and the seventeenth century, extension was substituted for localization.

Today the site has been substituted for extension which itself had replaced emplacement. The site is defined by relations of proximity between points or elements; formally, we can describe these relations as series, trees, or grids. Moreover, the importance of the site as a problem in contemporary technical work is well known: the storage of data or of the intermediate results of a calculation in the memory of a machine, the circulation of discrete elements with a random output (automobile traffic is a simple case, or indeed the sounds on a telephone line); the identification of marked or coded elements inside a set that may be randomly distributed, or may be arranged according to single or to multiple classifications.

In a still more concrete manner, the problem of siting or placement arises for mankind in terms of demography. This problem of the human site or living space is not simply that of knowing whether there will be enough space for men in the world-a problem that is certainly quite important-but also that of knowing what relations of propinquity, what type of storage, circulation, marking, and classification of human elements should be adopted in a given situation in order to achieve a given end. Our epoch is one in which space takes for us the form of relations among sites.

In any case I believe that the anxiety of our era has to do fundamentally with space, no doubt a great deal more than with time. Time probably appears to us only as one of the various distributive operations that are possible for the elements that are spread out in space,

Now, despite all the techniques for appropriating space, despite the whole network of knowledge that enables us to delimit or to formalize it, contemporary space is perhaps still not entirely desanctified (apparently unlike time, it would seem, which was detached from the sacred in the nineteenth century). To be sure a certain theoretical desanctification of space (the one signaled by Galileo's work) has occurred, but we may still not have reached the point of a practical desanctification of space. And perhaps our life is still governed by a certain number of oppositions that remain inviolable, that our institutions and practices have not yet dared to break down. These are oppositions that we regard as simple givens: for example between private space and public space, between family space and social space, between cultural space and useful space, between the space of leisure and that of work. All these are still nurtured by the hidden presence of the sacred.

Bachelard's monumental work and the descriptions of phenomenologists have taught us that we do not live in a homogeneous and empty space, but on the contrary in a space thoroughly imbued with quantities and perhaps thoroughly fantasmatic as well. The space of our primary perception, the space of our 
dreams and that of our passions hold within themselves qualities that seem intrinsic: there is a light, ethereal, transparent space, or again a dark, rough, encumbered space; a space from above, of summits, or on the contrary a space from below of mud; or again a space that can be flowing like sparkling water, or space that is fixed, congealed, like stone or crystal. Yet these analyses, while fundamental for reflection in our time, primarily concern internal space. I should like to speak now of external space.

The space in which we live, which draws us out of ourselves, in which the erosion of our lives, our time and our history occurs, the space that claws and gnaws at us, is also, in itself, a heterogeneous space. In other words, we do not live in a kind of void, inside of which we could place individuals and things. We do not live inside a void that could be colored with diverse shades of light, we live inside a set of relations that delineates sites which are irreducible to one another and absolutely not superimposable on one another.

Of course one might attempt to describe these different sites by looking for the set of relations by which a given site can be defined. For example, describing the set of relations that define the sites of transportation, streets, trains (a train is an extraordinary bundle of relations because it is something through which one goes, it is also something by means of which one can go from one point to another, and then it is also something that goes by). One could describe, via the cluster of relations that allows them to be defined, the sites of temporary relaxation-cafes, cinemas, beaches. Likewise one could describe, via its network of relations, the closed or semi-closed sites of rest-the house, the bedroom, the bed, et cetera. But among all these sites, I am interested in certain ones that have the curious property of being in relation with all the other sites, but in such a way as to suspect, neutralize, or invent the set of relations that they happen to designate, mirror, or reflect. These spaces, as it were, which are linked with all the others, which however contradict all the other sites, are of two main types.

\section{HETEROTOPIAS}

First there are the utopias. Utopias are sites with no real place. They are sites that have a general relation of direct or inverted analogy with the real space of Society. They present society itself in a perfected form, or else society turned upside down, but in any case these utopias are fundamentally unreal spaces.

There are also, probably in every culture, in every civilization, real places - places that do exist and that are formed in the very founding of societywhich are something like counter-sites, a kind of effectively enacted utopia in which the real sites, all the other real sites that can be found within the culture, are simultaneously represented, contested, and inverted. Places of this kind are 
outside of all places, even though it may be possible to indicate their location in reality. Because these places are absolutely different from all the sites that they reflect and speak about, I shall call them, by way of contrast to utopias, heterotopias. I believe that between utopias and these quite other sites, these heterotopias, there might be a sort of mixed, joint experience, which would be the mirror. The mirror is, after all, a utopia, since it is a placeless place. In the mirror, I see myself there where I am not, in an unreal, virtual space that opens up behind the surface; I am over there, there where I am not, a sort of shadow that gives my own visibility to myself, that enables me to see myself there where I am absent: such is the utopia of the mirror. But it is also a heterotopia in so far as the mirror does exist in reality, where it exerts a sort of counteraction on the position that I occupy. From the standpoint of the mirror I discover my absence from the place where I am since I see myself over there. Starting from this gaze that is, as it were, directed toward me, from the ground of this virtual space that is on the other side of the glass, I come back toward myself; I begin again to direct my eyes toward myself and to reconstitute myself there where I am. The mirror functions as a heterotopia in this respect: it makes this place that I occupy at the moment when I look at myself in the glass at once absolutely real, connected with all the space that surrounds it, and absolutely unreal, since in order to be perceived it has to pass through this virtual point which is over there.

As for the heterotopias as such, how can they be described? What meaning do they have? We might imagine a sort of systematic description-I do not say a science because the term is too galvanized now - that would, in a given society, take as its object the study, analysis, description, and 'reading' (as some like to say nowadays) of these different spaces, of these other places. As a sort of simultaneously mythic and real contestation of the space in which we live, this description could be called heterotopology.

Its first principle is that there is probably not a single culture in the world that fails to constitute heterotopias. That is a constant of every human group. But the heterotopias obviously take quite varied forms, and perhaps no one absolutely universal form of heterotopia would be found. We can however class them in two main categories.

In the so-called primitive societies, there is a certain form of heterotopia that I would call crisis heterotopias, i.e., there are privileged or sacred or forbidden places, reserved for individuals who are, in relation to society and to the human environment in which they live, in a state of crisis: adolescents, menstruating women, pregnant women, the elderly, etc. In out society, these crisis heterotopias are persistently disappearing, though a few remnants can still be found. For example, the boarding school, in its nineteenth-century form, or military service for young men, have certainly played such a role, as the first manifestations of sexual virility were in fact supposed to take place "elsewhere" 
than at home. For girls, there was, until the middle of the twentieth century, a tradition called the "honeymoon trip" which was an ancestral theme. The young woman's deflowering could take place "nowhere" and, at the moment of its occurrence the train or honeymoon hotel was indeed the place of this nowhere, this heterotopia without geographical markers.

But these heterotopias of crisis are disappearing today and are being replaced, I believe, by what we might call heterotopias of deviation: those in which individuals whose behavior is deviant in relation to the required mean or norm are placed. Cases of this are rest homes and psychiatric hospitals, and of course prisons, and one should perhaps add retirement homes that are, as it were, on the borderline between the heterotopia of crisis and the heterotopia of deviation since, after all, old age is a crisis, but is also a deviation since in our society where leisure is the rule, idleness is a sort of deviation.

The second principle of this description of heterotopias is that a society, as its history unfolds, can make an existing heterotopia function in a very different fashion; for each heterotopia has a precise and determined function within a society and the same heterotopia can, according to the synchrony of the culture in which it occurs, have one function or another.

As an example I shall take the strange heterotopia of the cemetery. The cemetery is certainly a place unlike ordinary cultural spaces. It is a space that is however connected with all the sites of the city, state or society or village, etc., since each individual, each family has relatives in the cemetery. In western culture the cemetery has practically always existed. But it has undergone important changes. Until the end of the eighteenth century, the cemetery was placed at the heart of the city, next to the church. In it there was a hierarchy of possible tombs. There was the charnel house in which bodies lost the last traces of individuality, there were a few individual tombs and then there were the tombs inside the church. These latter tombs were themselves of two types, either simply tombstones with an inscription, or mausoleums with statues. This cemetery housed inside the sacred space of the church has taken on a quite different cast in modern civilizations, and curiously, it is in a time when civilization has become 'atheistic,' as one says very crudely, that western culture has established what is termed the cult of the dead.

Basically it was quite natural that, in a time of real belief in the resurrection of bodies and the immortality of the soul, overriding importance was not accorded to the body's remains. On the contrary, from the moment when people are no longer sure that they have a soul or that the body will regain life, it is perhaps necessary to give much more attention to the dead body, which is ultimately the only trace of our existence in the world and in language. In any case, it is from the beginning of the nineteenth century that everyone has a right to her or his own little box for her or his own little personal decay, but on the 
other hand, it is only from that start of the nineteenth century that cemeteries began to be located at the outside border of cities. In correlation with the individualization of death and the bourgeois appropriation of the cemetery, there arises an obsession with death as an 'illness.' The dead, it is supposed, bring illnesses to the living, and it is the presence and proximity of the dead right beside the houses, next to the church, almost in the middle of the street, it is this proximity that propagates death itself. This major theme of illness spread by the contagion in the cemeteries persisted until the end of the eighteenth century, until, during the nineteenth century, the shift of cemeteries toward the suburbs was initiated. The cemeteries then came to constitute, no longer the sacred and immortal heart of the city, but the other city, where each family possesses its dark resting place.

Third principle. The heterotopia is capable of juxtaposing in a single real place several spaces, several sites that are in themselves incompatible. Thus it is that the theater brings onto the rectangle of the stage, one after the other, a whole series of places that are foreign to one another; thus it is that the cinema is a very odd rectangular room, at the end of which, on a two-dimensional screen, one sees the projection of a three-dimensional space, but perhaps the oldest example of these heterotopias that take the form of contradictory sites is the garden. We must not forget that in the Orient the garden, an astonishing creation that is now a thousand years old, had very deep and seemingly superimposed meanings. The traditional garden of the Persians was a sacred space that was supposed to bring together inside its rectangle four parts representing the four parts of the world, with a space still more sacred than the others that were like an umbilicus, the navel of the world at its center (the basin and water fountain were there); and all the vegetation of the garden was supposed to come together in this space, in this sort of microcosm. As for carpets, they were originally reproductions of gardens (the garden is a rug onto which the whole world comes to enact its symbolic perfection, and the rug is a sort of garden that can move across space). The garden is the smallest parcel of the world and then it is the totality of the world. The garden has been a sort of happy, universalizing heterotopia since the beginnings of antiquity (our modern zoological gardens spring from that source).

Fourth principle. Heterotopias are most often linked to slices in time-which is to say that they open onto what might be termed, for the sake of symmetry, heterochronies. The heterotopia begins to function at full capacity when men arrive at a sort of absolute break with their traditional time. This situation shows us that the cemetery is indeed a highly heterotopic place since, for the individual, the cemetery begins with this strange heterochrony, the loss of life, and with this quasi-eternity in which her permanent lot is dissolution and disappearance. 
From a general standpoint, in a society like ours heterotopias and heterochronies are structured and distributed in a relatively complex fashion. First of all, there are heterotopias of indefinitely accumulating time, for example museums and libraries, Museums and libraries have become heterotopias in which time never stops building up and topping its own summit, whereas in the seventeenth century, even at the end of the century, museums and libraries were the expression of an individual choice. By contrast, the idea of accumulating everything, of establishing a sort of general archive, the will to enclose in one place all times, all epochs, all forms, all tastes, the idea of constituting a place of all times that is itself outside of time and inaccessible to its ravages, the project of organizing in this way a sort of perpetual and indefinite accumulation of time in an immobile place, this whole idea belongs to our modernity. The museum and the library are heterotopias that are proper to western culture of the nineteenth century.

Opposite these heterotopias that are linked to the accumulation of time, there are those linked, on the contrary, to time in its most flowing, transitory, precarious aspect, to time in the mode of the festival. These heterotopias are not oriented toward the eternal, they are rather absolutely temporal [chroniques]. Such, for example, are the fairgrounds, these' marvelous empty sites on the outskirts of cities that teem once or twice a year with stands, displays, heteroclite objects, wrestlers, snakewomen, fortune-tellers, and so forth. Quite recently, a new kind of temporal heterotopia has been invented: vacation villages, such as those Polynesian villages that offer a compact three weeks of primitive and eternal nudity to the inhabitants of the cities. You see, moreover, that through the two forms of heterotopias that come together here, the heterotopia of the festival and that of the eternity of accumulating time, the huts of Djerba are in a sense relatives of libraries and museums, for the rediscovery of Polynesian life abolishes time; yet the experience is just as much the rediscovery of time, it is as if the entire history of humanity reaching back to its origin were accessible in a sort of immediate knowledge.

Fifth principle. Heterotopias always presuppose a system of opening and closing that both isolates them and makes them penetrable. In general, the heterotopic site is not freely accessible like a public place. Either the entry is compulsory, as in the case of entering a barracks or a prison, or else the individual has to submit to rites and purifications. To get in one must have a certain permission and make certain gestures. Moreover, there are even heterotopias that are entirely consecrated to these activities of purification-purification that is partly religious and partly hygienic, such as the hammin of the Moslems, or else purification that appears to be purely hygienic, as in Scandinavian saunas.

There are others, on the contrary, that seem to be pure and simple openings, but that generally hide curious exclusions. Everyone can enter into the 
heterotopic sites, but in fact that is only an illusion-we think we enter where we are, by the very fact that we enter, excluded. I am thinking for example, of the famous bedrooms that existed on the great farms of Brazil and elsewhere in South America. The entry door did not lead into the central room where the family lived, and every individual or traveler who came by had the right to open this door, to enter into the bedroom and to sleep there for a night. Now these bedrooms were such that the individual who went into them never had access to the family's quarter the visitor was absolutely the guest in transit, was not really the invited guest. This type of heterotopia, which has practically disappeared from our civilizations, could perhaps be found in the famous American motel rooms where a man goes with his car and his mistress and where illicit sex is both absolutely sheltered and absolutely hidden, kept isolated without however being allowed out in the open.

Sixth principle. The last trait of heterotopias is that they have a function in relation to all the space that remains. This function unfolds between two extreme poles. Either their role is to create a space of illusion that exposes every real space, all the sites inside of which human life is partitioned, as still more illusory (perhaps that is the role that was played by those famous brothels of which we are now deprived). Or else, on the contrary, their role is to create a space that is other, another real space, as perfect, as meticulous, as well arranged as ours is messy, ill constructed, and jumbled. This latter type would be the heterotopia, not of illusion, but of compensation, and I wonder if certain colonies have not functioned somewhat in this manner. In certain cases, they have played, on the level of the general organization of terrestrial space, the role of heterotopias. I am thinking, for example, of the first wave of colonization in the seventeenth century, of the Puritan societies that the English had founded in America and that were absolutely perfect other places. I am also thinking of those extraordinary Jesuit colonies that were founded in South America: marvelous, absolutely regulated colonies in which human perfection was effectively achieved. The Jesuits of Paraguay established colonies in which existence was regulated at every turn. The village was laid out according to a rigorous plan around a rectangular place at the foot of which was the church; on one side, there was the school; on the other, the cemetery, and then, in front of the church, an avenue set out that another crossed at right angles; each family had its little cabin along these two axes and thus the sign of Christ was exactly reproduced. Christianity marked the space and geography of the American world with its fundamental sign.

The daily life of individuals was regulated, not by the whistle, but by the bell. Everyone was awakened at the same time, everyone began work at the same time; meals were at noon and five o'clock, then came bedtime, and at midnight 
came what was called the marital wake-up, that is, at the chime of the churchbell, each person carried out her/his duty.

Brothels and colonies are two extreme types of heterotopia, and if we think, after all, that the boat is a floating piece of space, a place without a place, that exists by itself, that is closed in on itself and at the same time is given over to the infinity of the sea and that, from port to port, from tack to tack, from brothel to brothel, it goes as far as the colonies in search of the most precious treasures they conceal in their gardens, you will understand why the boat has not only been for our civilization, from the sixteenth century until the present, the great instrument of economic development (I have not been speaking of that today), but has been simultaneously the greatest reserve of the imagination. The ship is the heterotopia par excellence. In civilizations without boats, dreams dry up, espionage takes the place of adventure, and the police take the place of pirates.

This text, entitled "Des Espace Autres," and published by the French journal Architecture /Mouvement/ Continuité in October, 1984, was the basis of a lecture given by Michel Foucault in March 1967.

Although not reviewed for publication by the author and thus not part of the official corpus of his work, the manuscript was relaeased into the public domain for an exhibition in Berlin shortly before Michel Foucault's death. Translated from the French by Jay Miskowiec. 